\title{
Influence of Camellia sinensis on Broilers Performance
}

\section{Mohsin Ali Alias Mehran Khan Solangi ${ }^{1}$, Gulfam Ali Mughal ${ }^{1}$, Asad Ali Khaskheli ${ }^{*}$, Turab Ali Korejo ${ }^{3}$, Nazeer Ahmed Rajput ${ }^{2}$, Qurban Ali Memon ${ }^{3}$ and Maqsood Ahmed Kumbhar ${ }^{4}$}

${ }^{1}$ Department of Animal Nutrition, Sindh Agriculture University, Tandojam, Pakistan; ${ }^{2}$ Department of Poultry Husbandry, Sindh Agriculture University, Tandojam, Pakistan; ${ }^{3}$ Department of Livestock Management, Sindh Agriculture University, Tandojam, Pakistan; ${ }^{4}$ Department of Veterinary Parasitology, Sindh Agriculture University, Tandojam.

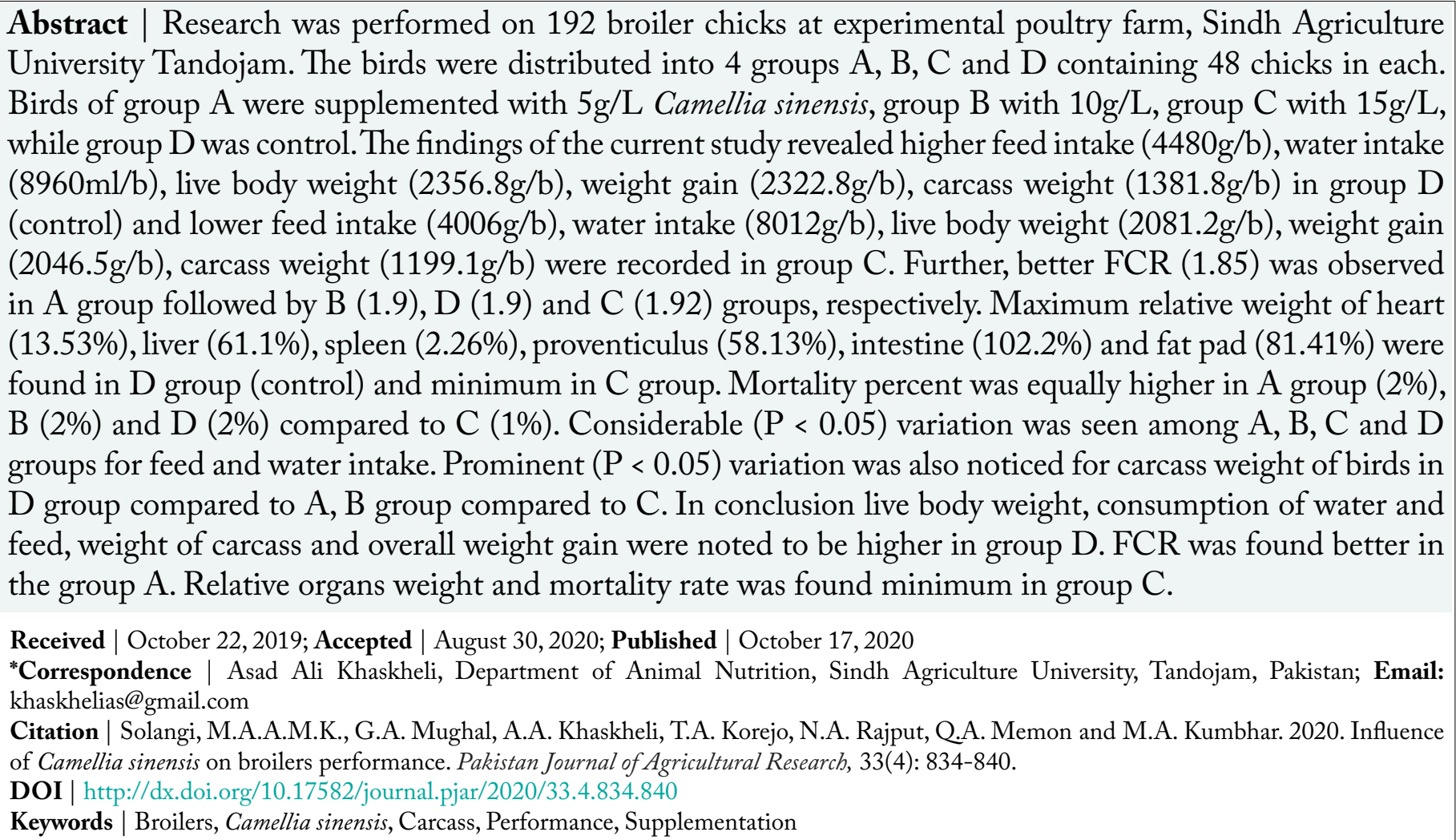

\section{Introduction}

$C$ amellia sinensis is one of the delicious refreshment products. This product was discovered in 2737 BC by a chines scientist Shen Nung. It is actually perennial plant though have white colored flowers, green colored fruits with 2 to 3 seeds. The color and flavor of Camellia sinensis is concerned to the method used for the processing of leaves (Perumalla and Hettiarachchy, 2011). Camellia sinensis is also notorious by its common name i.e. green tea. It is unfermented and un-oxidized product of leaves of Camellia sinensis. It contains polyphenolic compounds called as flavonoids. Catechins are the main flavonoids found in Camellia sinensis (Maron et al., 2003). These compounds have variety of health benefits including antioxidant, anti-mutagenic, anticancer, antibacterial, antitoxin, antiviral, antifungal and antiosteoporotic etc (Sommer et al., 2010). In addition to catechins Camellia sinensis also contains some other active biological compounds such as caffeine, methylxanthines, theobromine and theophylline. 
These all active compounds in Camellia sinensis are highly effective against lipid peroxides induced disease like which infect the blood vessels, kidneys and liver (Friedman, 2007).

Camellia sinensis has also been reported as supportive supplement for avian species. In a study supplementation epigallocatechin gallate found to beneficial in heat stressed Japanese quails (Tuzcu et al., 2008). Positive influence of Camellia sinensis was also observed against poultry infections including coccidiosis and influenza (Jang et al., 2007). The leaves as well as by-products of Camellia sinensis can be provided to the broilers as a feed supplement in order to reduce mortality and improve performance (Deryabin et al., 2008; Uuganbayar et al., 2005). Yang et al. (2003) demonstrated that feeding of different levels of Camellia sinensis to animals declines the level of fatty acids and cholesterol in muscles and plasma and also improve the meat quality. Camellia sinensis in term of leaves, flowers, byproducts, extracts and polyphenols has been used in different poultry species to improve the birds' performance (Kajiya et al., 2004). We hypothesize that Camellia sinensis at higher supplementation dose in broilers could be supportive. Therefore, this study was planned whereby the main objective was to assess effects of Camellia sinensis on broilers performance.

\section{Materials and Methods}

\section{Experimental design and procedures}

Total 192 broiler chicks having age of 1 day were purchased and shifted to experimental poultry farm at Sindh Agriculture University Tandojam. Initial weight of chicks were recorded on arrival and then allocated into 4 groups including $\mathrm{A}, \mathrm{B}, \mathrm{C}$ and D, containing 48 chicks in each. Groups were subdivided with 3 replicates containing 16 chicks in each. The same housing and bedding facility was provided to each group. Chicks in group A were given $5 \mathrm{~g} / \mathrm{L}$ Camellia sinensis, in group B $10 \mathrm{~g} / \mathrm{L}$ and group C $15 \mathrm{~g} / \mathrm{L}$ in their normal diet, however group $\mathrm{D}$ was kept as control and Camellia sinensis free diet was provided to birds (Table 1 ).

Experimental trial was carried out till 36 days and data regarding different study parameters like live body weight, water consumption, feed intake, carcass weight, weight gain, feed conversion ratio (FCR), relative organs weight (\% edible and non edible) and mortality percentage was recorded.

Water consumption and feed intake was computed with below given formula. Supply and refusal of feed and water to the birds/day were recorded and values were put in the following formula for calculating the feed/water consumption:

Feed Total amount of offered feed or water-Total amount of refused feed or water $\overline{\text { water consumption }}=\frac{\text { Total number of birds }}{\text { Totalamount }}$

For measuring the total initial live body weight, 4 birds/replicate were selected randomly on day $1^{\text {st }}$ and weighed using electric weight balance. Further weight was recorded on day $36^{\text {th }}$ i.e. end of experiment and values were put in the below given formula for computing the weight gain.

Weight gain = Initial weight of bird-final weight of bird

Wight of carcass was computed following dressing the carcass. The dressing percentage was computed using below given equation.

$$
\text { Dressing percentage }=\frac{\text { Weight of carcass }(\mathrm{kg})}{\text { live weight of body }(\mathrm{kg})} \times 100
$$

For calculating FCR, aggregate weights all chick and feed intake were recorded on day $36^{\text {th }}$. Values were fixed in the following formula.

$$
\text { FCR }=\frac{\text { Total quantity of feed consumed by chicks }}{\text { Aggregate weight gain of all chicks }} \times 100
$$

Relative organs weight was recorded using four slaughtered birds from each group. Edible and nonedible organs including gizzard, heart, liver, proventiculus spleen, feathers, feet, head, and intestines were weighed. The relative organ weight was computed using below given equation.

$$
\text { Relative organs weight }=\frac{\text { Wight of organ }}{\text { live weight of body }} \times 100
$$

Mortality percentage was calculated by recording total number of live and died birds during experimental period. Values were put in the following formula for computing the final mortality rate.

$$
\text { Mortality }(\%)=\frac{\text { Total broiler died }}{\text { Total broiler reared }} \times 100
$$


Table 1: Diet composition of proposed rations.

\begin{tabular}{|c|c|c|c|c|c|c|c|c|}
\hline \multirow[t]{3}{*}{ Ingredients } & \multicolumn{4}{|c|}{ Starter ration } & \multicolumn{4}{|c|}{ Finisher ration } \\
\hline & \multicolumn{4}{|c|}{ Groups } & \multicolumn{4}{|c|}{ Groups } \\
\hline & A & B & $\mathrm{C}$ & $\mathrm{D}$ & A & B & $\mathrm{C}$ & $\mathrm{D}$ \\
\hline Guar meal & 2 & 2 & 2 & 2 & 2 & 2 & 2 & 2 \\
\hline Soybean meal & 5 & 5 & 5 & 5 & 5 & 5 & 5 & 5 \\
\hline Sunflower Meal & 9 & 9 & 9 & 9 & 9 & 9 & 9 & 9 \\
\hline Rice Polish & 17.5 & 17 & 16.5 & 18 & 19.5 & 19 & 18.5 & 20 \\
\hline Canola Meal & 10 & 10 & 10 & 10 & 10 & 10 & 10 & 10 \\
\hline Fish Meal & 6 & 6 & 6 & 6 & 4 & 4 & 4 & 4 \\
\hline Corn meal & 20 & 20 & 20 & 20 & 20 & 20 & 20 & 20 \\
\hline Rice meal & 18 & 18 & 18 & 18 & 18 & 18 & 18 & 18 \\
\hline Cotton gluten $30 \%$ & 5 & 5 & 5 & 5 & 5 & 5 & 5 & 5 \\
\hline Cotton gluten $60 \%$ & 3 & 3 & 3 & 3 & 3 & 3 & 3 & 3 \\
\hline DLM & 0.5 & 0.5 & 0.5 & 0.5 & 0.5 & 0.5 & 0.5 & 0.5 \\
\hline L-lysine & 1.5 & 1.5 & 1.5 & 1.5 & 1 & 1 & 1 & 1 \\
\hline Dicalcium phosphate & 0.5 & 0.5 & 0.5 & 0.5 & 0.5 & 0.5 & 0.5 & 0.5 \\
\hline Lime Stone & 1.5 & 1.5 & 1.5 & 1.5 & 2 & 2 & 2 & 2 \\
\hline Camellia sinensis & 5 & 10 & 15 & 0 & 5 & 10 & 15 & 0 \\
\hline \multirow[t]{2}{*}{ Total } & 100 & 100 & 100 & 100 & 100 & 100 & 100 & 100 \\
\hline & \multicolumn{8}{|c|}{ Calculated nutrients composition } \\
\hline M.E (kcal/kg) & 2412 & 2405 & 2401 & 2407 & 2719 & 2794 & 2787 & 2709 \\
\hline C.P (\%) & 22.5 & 22.2 & 22.6 & 22.4 & 19.2 & 19.4 & 19.3 & 19.6 \\
\hline E.E (\%) & 1.8 & 1.7 & 1.9 & 1.8 & 2.6 & 2.8 & 2.9 & 2.7 \\
\hline C.F (\%) & 2.8 & 3.1 & 3.2 & 2.9 & 2.7 & 2.9 & 3.1 & 2.8 \\
\hline
\end{tabular}

\section{Data analysis}

Data was analyzed using statistical software i.e. JMP, SAS 9.0, SAS Institute Inc., Cary, NC. Statistical test namely One Way Analysis of Variance was applied. Difference was considered significant at $\mathrm{P}<0.05$.

\section{Results and Discussion}

\section{Feed intake}

Result regarding the feed intake of birds influenced at different levels of Camellia sinensis supplementation are shown in Figure 1. Significant $(\mathrm{P}<0.05)$ difference was found for feed intake of chicks in group A, B, $\mathrm{C}$ and D. Higher values for feed intake $(4480 \mathrm{~g} / \mathrm{b})$ was observed in control group, while feed intake $(4006 \mathrm{~g} / \mathrm{b})$ was found lower in group C, where chicks' diet was supplemented with $15 \mathrm{~g} / \mathrm{L}$ Camellia sinensis.

\section{Water intake}

The water intake of birds as influenced by different levels of Camellia sinensis supplementation is shown in Figure 2. Figure depicts prominent $(\mathrm{P}<0.05)$ variation amongst groups $\mathrm{A}, \mathrm{B}, \mathrm{C}$ and $\mathrm{D}$ for water intake of chicks. Maximum water intake $(8960 \mathrm{ml} / \mathrm{b})$ was noted in group $\mathrm{D}$ (control) and minimum water intake $(8012 \mathrm{ml} / \mathrm{b})$ was seen in group C $(15 \mathrm{~g} / \mathrm{L}$ Camellia sinensis).

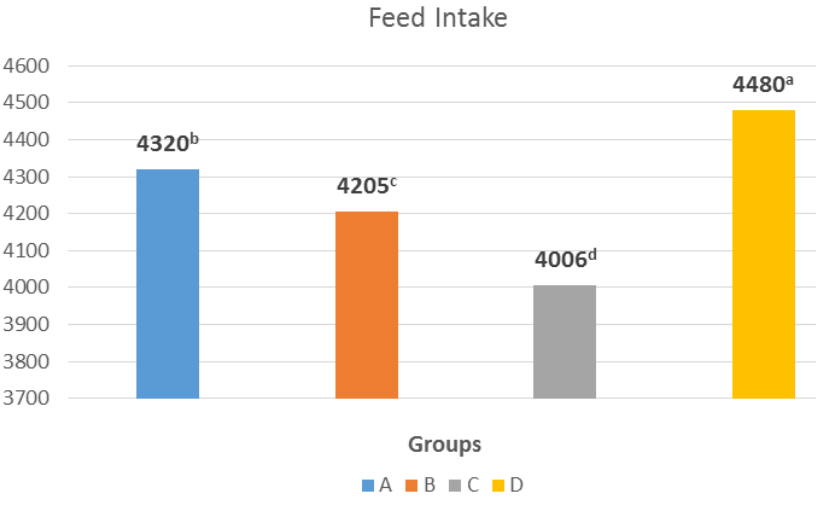

Figure 1: Influence of Camellia sinensis supplementation on feed intake $(g / b) . S E \pm=12.377 ; L S D$ at $0.05=24.470 ; P$-value $=0.0001$.

\section{Live body weight}

Live body weight of chicks as influenced by different levels of Camellia sinensis supplementation is shown in Figure 3. There was considerable $(\mathrm{P}<0.05)$ difference within $\mathrm{A}, \mathrm{B}$ and $\mathrm{C}$ groups. However, between groups 
$\mathrm{A}$ and $\mathrm{D}$ non-considerable $(\mathrm{P}>0.05)$ difference was observed. Maximum live body weight $(2356.8 \mathrm{~g} / \mathrm{b})$ was noted in group D (control) and minimum live body weight $(2081.2 \mathrm{~g} / \mathrm{b})$ was recorded in group C (15g/L Camellia sinensis).

Water Intake

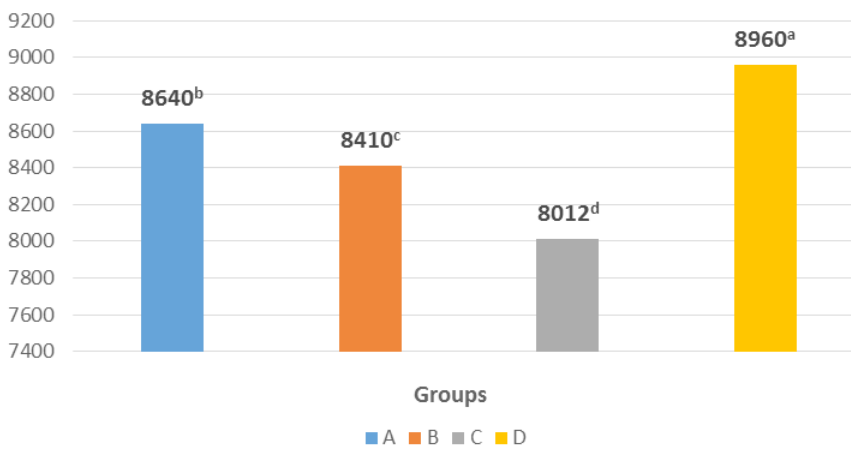

Figure 2: Influence of Camellia sinensis supplementation on water intake (ml/b). SE $\pm=24.460 ;$ LSD at 0.05= 48.358; P-value= 0.0001 .

Live Body Weight

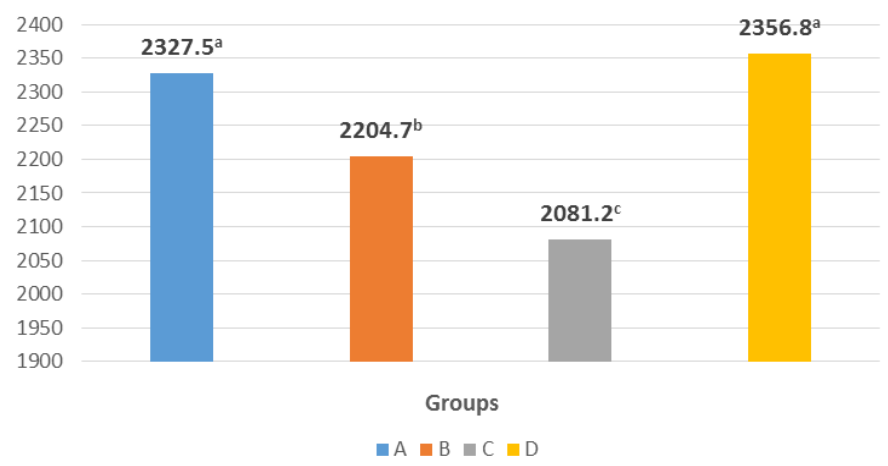

Figure 3: Influence of Camellia sinensis supplementation on live body weight $(g / b)$. $S E \pm=31.981 ; L S D$ at $0.05=66.712 ; P$-value $=$ 0.0001 .

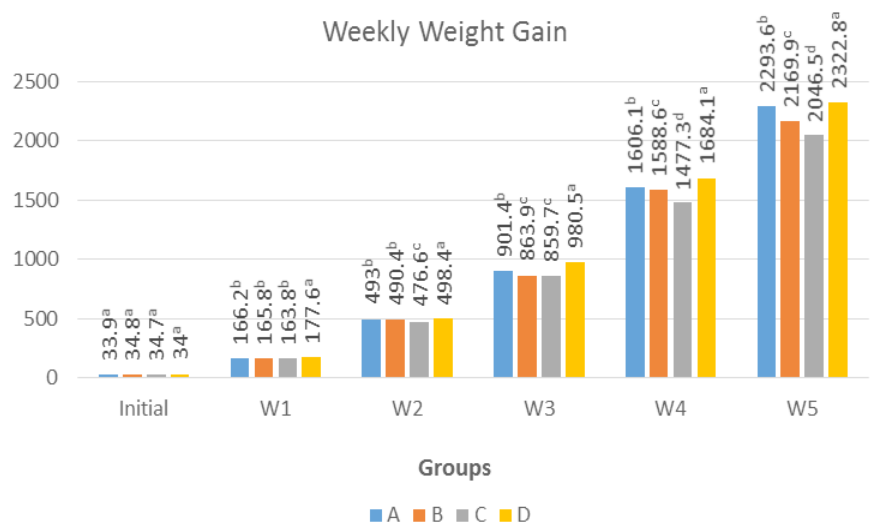

$\begin{array}{lllllll} & \text { Initial } & \text { Week 1 } & \text { Week 2 } & \text { Week 3 } & \text { Week 4 } & \text { Week 5 } \\ \text { SE } \pm & 1.5645 & 6.4357 & 7.3152 & 2.2010 & 38.763 & 31.981 \\ \text { LSD at } 0.05 & 3.1730 & 13.052 & 15.117 & 5.3070 & 78.615 & 66.712 \\ \text { P-value } & 0.9113 & 0.1488 & 0.0074 & 0.0030 & 0.0000 & 0.0001\end{array}$

Figure 4: Influence of Camellia sinensis supplementation on weekly weight gain $(g / b)$.
Weight gain

The weight gain of birds as influenced by different levels of Camellia sinensis supplementation is given in Figure 4. Prominent $(\mathrm{P}<0.05)$ variation was observed for weight gain of chicks in all groups for $1^{\text {st }}, 2^{\text {nd }}, 3^{\text {rd }}$, $4^{\text {th }}$ and $5^{\text {th }}$ week. Maximum weight gain $(177.6,498.4$, $980.5,1684.1$ and $2322.8 \mathrm{~g} / \mathrm{b}$ ) was noted in group D (control) and minimum weight gain (163.8, 476.6, $859.7,1477.3$ and $2046.5 \mathrm{~g} / \mathrm{b}$ ) was noticed in group C (15g/L Camellia sinensis) for week 1, 2, 3, 4 and 5, respectively.

\section{Carcass weight}

The carcass weight of birds as influenced by different levels of Camellia sinensis supplementation is shown in Figure 5. There was prominent $(\mathrm{P}<0.05)$ variation in carcass weight of chicks for group $\mathrm{D}$ with $\mathrm{A}, \mathrm{B}$ and $\mathrm{C}$, while non-significant $(\mathrm{P}>0.05)$ difference between groups $\mathrm{A}$ and $\mathrm{B}$, correspondingly. Higher carcass weight $(1381.8 \mathrm{~g} / \mathrm{b})$ was noted in group D (control) and lower carcass weight $(1199.1 \mathrm{~g} / \mathrm{b})$ was observed in group C (15g/L Camellia sinensis).

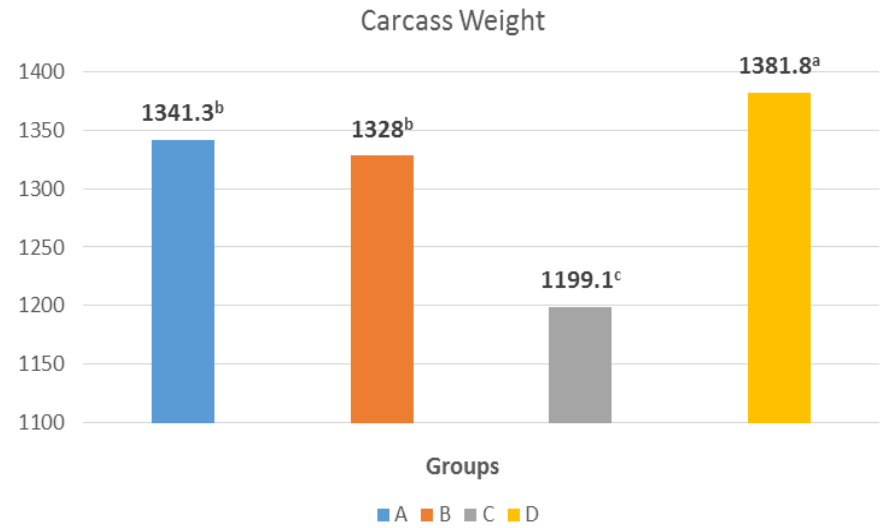

Figure 5: Influence of Camellia sinensis supplementation on carcass weight $(g / b)$. SE $\pm=42.419 ;$ LSD at $0.05=88.484 ;$ P-value $=$ 0.0022 .

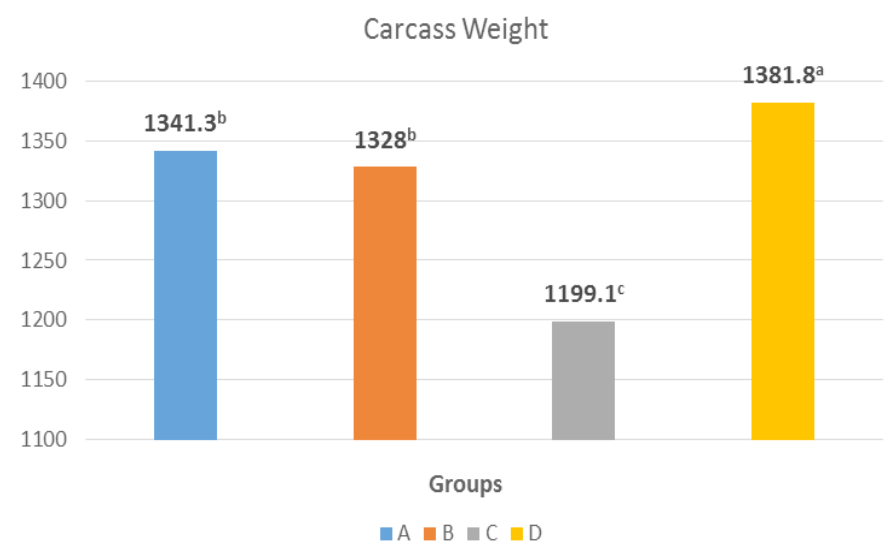

Figure 6: Influence of Camellia sinensis supplementation on feed conversion ratio. $S E \pm=2.8834 ; L S D$ at $0.05=5.2319 ; P-$ value $=$ 0.0384 . 
Feed conversion ratio (FCR)

FCR as influenced by different levels of Camellia sinensis supplementation is shown in Figure 6 . Comparatively better FCR (1.85) was noticed in group A (5g/L Camellia sinensis) followed by group $\mathrm{B}, \mathrm{D}$ (1.9) and C (1.92). Statistically there was prominent $(\mathrm{P}<0.05)$ variation within $\mathrm{A}, \mathrm{B}, \mathrm{C}$ and $\mathrm{D}$ groups.

\section{Relative organs weight}

Results concerning relative weights of liver, heart, spleen, proventiculus, intestine and fat pad as influenced by different levels of Camellia sinensis supplementation are shown in Figure 7. No considerable $(\mathrm{P}>0.05)$ change was seen among relative weights of liver, heart, spleen, proventiculus, intestines and fat pad of groups A, B, C and D.

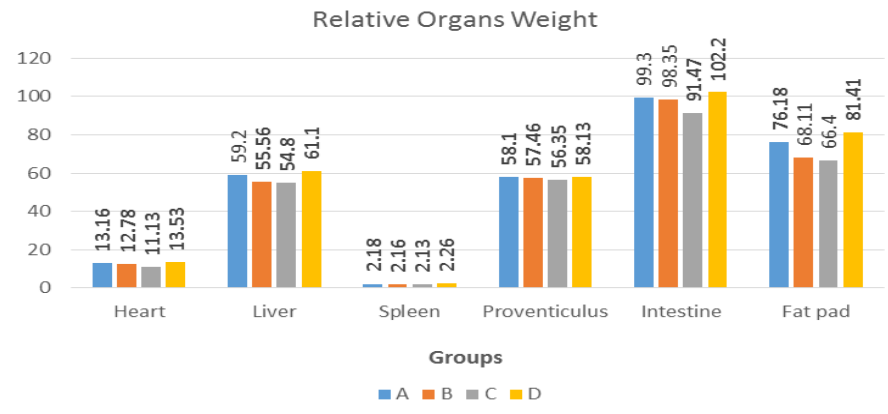

Heart Liver Spleen Proventiculus Intestine Fat pad $\begin{array}{lllllll}\mathrm{SE} \pm & 1.1304 & 3.1854 & 0.0938 & 2.5472 & 4.9448 & 10.064\end{array}$ LSD at $\begin{array}{lllllll}0.05 & 2.3580 & 6.6447 & 0.1957 & 5.3134 & 10.315 & 20.993\end{array}$ $\begin{array}{lllllll}\mathrm{P} \text {-value } & 0.1880 & 0.1875 & 0.5457 & 0.8854 & 0.2010 & 0.4234\end{array}$

Figure 7: Influence of Camellia sinensis supplementation on relative organs weight (\%).

\section{Mortality}

Regarding mortality rate results are depicted in the Figure 8. It is indicated in the figure that the mortality percentage (\%) was equally higher among groups $\mathrm{A}$ (2\%), B (2\%) and D (2\%) compared to group C (1\%).

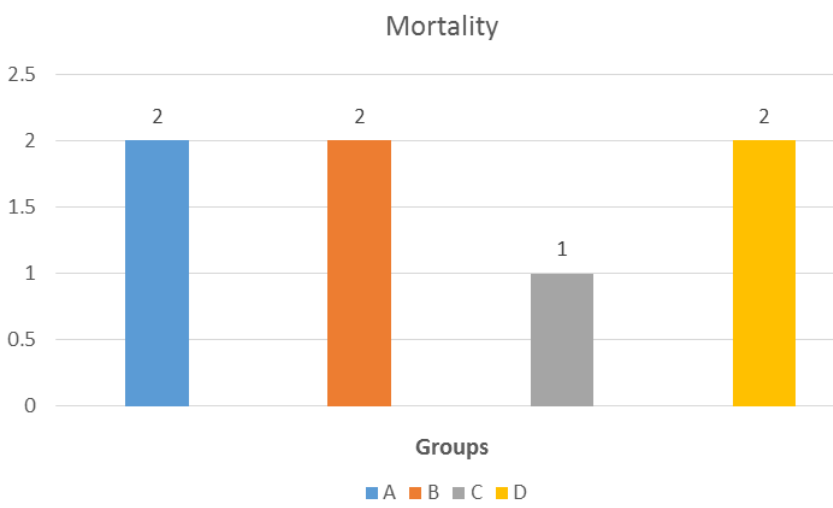

Figure 8: Influence of Camellia sinensis supplementation on mortality (\%).
Findings of this study shows that broilers managed in control group D (without supplementation of green tea) consumed higher feed and water intake compared to broilers managed in treatment groups $\mathrm{A}, \mathrm{B}$ and $\mathrm{C}$ (supplemented with 5,10 and $15 \mathrm{~g} / \mathrm{L}$ of green tea). The decrease in feed and water intake are linked with intoxicating of green tea because it contains high level of catechin that possessed an inhibitory influence on absorption in the intestine (Ikeda et al., 1992). Our findings are agree with the study of (Biswas et al., 2000). Biswas and Wakita (2001) reported that supplementation of Camellia sinensis powder (0.6\%) decreases the feed and water intake.

Current study showed that broilers managed under control group D (without supplementation of green tea) attained higher carcass and live body weight contrast to the broilers managed under treated groups including A, B and C (supplemented with 5, 10 and $15 \mathrm{~g} / \mathrm{L}$ of Camellia sinensis). The decreasing pattern in live body weight and carcass weight are associated with the feed intake of broiler. Supplementation of Camellia sinensis powder decreased weight gain as well as carcass weight at higher supplementation dose. Kaneko et al, (2001) stated that 1, 2.5 and $5 \%$ of Camellia sinensis linearly reduce weight gain and carcass weight of the broilers chicks. Likewise, Uuganbayar (2004) indicated that 1 to $1.5 \%$ green tea supplementation influences the broilers. It reduces the weight gain and carcass weight of chicks. Relevant findings were observed by (Cao et al., 2005) who indicated carcass weight and live weight gain are favored by supplementation of Camellia sinensis.

Further, present study indicated that broilers managed in group A (supplemented with $5 \mathrm{~g} / \mathrm{L}$ of Camellia sinensis) showed better feed conversion ratio as compared to broilers managed in treatment groups B and C (supplemented with 10 and $15 \mathrm{~g} / \mathrm{L}$ of Camellia sinensis) as well as control group D (without Camellia sinensis supplementation). Improvement in feed conversion ratio is linked with minimum intake of feed. Findings are supported by Kaneko et al. (2001), who revealed that supplemental Camellia sinensis powder tended to improve FCR. Shomali et al. (2012) stated that Camellia sinensis tea powder in broiler ration displayed improvement in FCR.

Although some parts of the carcass were influenced but relative weight of organs was not significantly affected by Camellia sinensis. The thigh meat increased 
with 1.50 percent supplementation level, while wing meat was reduced among all treated groups. Percentage of abdominal fat significantly decreased by Camellia sinensis supplementation. Yang et al. (2003) and Guray et al. (2011) reported that with the increase of Camellia sinensis level, abdominal fat declines in broilers. It is also consistent with present observations about broiler chicks that Camellia sinensis powder prominently reduce the quantity of abdominal fat and cholesterol in blood and liver. It is also interesting to note that Camellia sinensis feeding enhances the behavioral activity of broilers, which is actually gap in our study (Biswas and Wakita, 2001).

\section{Conclusions and Recommendations}

Present study concludes that highest values for feed intake, water intake, live body weight, weight gain and carcass weight was noted in group D. Better FCR was recorded in group A. Least weight of heart, liver, spleen, proventiculus, intestine, fat pad and minimum mortality rate was observed in group $\mathrm{C}$.

\section{Novelty Statement}

Application of Camellia sinensis in broilers' diet is very unique aspect of our study. It has been first time explored in the world that the Camellia sinensis could be a beneficial plant product for broilers. Our study has proved that this plant product supports the performance of broilers and make poultry enterprise much economical.

\section{Author's Contribution}

Mohsin Ali Alias Mehran Khan Solangi, Gulfam Ali Mughal and Asad Ali Khaskheli: Conceived the idea, collected data and entered the data in SPSS for analysis.

Maqsood Ahmed Kumbhar: Provided technical input at every step.

Nazeer Ahmed Rajput: Did SPSS analysis.

Asad Ali Khaskheli: Wrote abstract, introduction, methodology, results and discussion, conclusion.

Turab Ali Kaurejo and: Contributed in overall management of the article.

Qurban Ali Memon: Contributed in the references.

\section{Conflict of interest}

The authors have declared no conflict of interest.
References

Biswas, A.H. and M. Wakita. 2001. Comparison of two dietary factors, green tea powder feeding and feed restriction, influencing laying performance and egg quality in hens. J. Poult. Sci., 25(3): 55-61.

Biswas, M.A.H. and M. Wakita. 2001. Effect of dietary Japanese green tea powder supplementation on feed utilization and carcass profiles in broilers. J. Poult. Sci., 38(5): 50-57. https://doi.org/10.2141/jpsa.38.50

Biswas, M.A.H., Y. Miyazaki, K. Nomura and M. Wakita. 2000. Influences of long-term feeding of Japanese green tea powder on laying performance and egg quality in hens. Asian Australas.J. Anim. Sci., 13(5): 980-985. https:// doi.org/10.5713/ajas.2000.980

Cao, B.H., Y. Karasawa and Y.M. Guo. 2005. Effects of green tea polyphenols and fructooligosaccharides in semi-purified diets on broiler performance and caecal microflora and their metabolites. Asian Australas. J. Anim. Sci., 18(4): 85-89. https://doi.org/10.5713/ ajas. 2005.85

Deryabin, P.G., D. K. Lvov, A. G. Botikov, V. Ivanov, T. Kalinovsky, A. Niedzwiecki, and M. Rath. 2008. Effects of a nutrient mixture on infectious properties of the highly pathogenic strain of avian influenza virus $\mathrm{A} / \mathrm{H} 5 \mathrm{~N} 1$.J.Anim. Nutr., 33(4): 85-97. https://doi.org/10.1002/ biof.5520330201

Friedman, M., 2007. Overview of antibacterial, antitoxin, antiviral, and antifungal activities of tea flavonoids and teas. Mol. Nutr. Food Res., 51(2): 116-134. https://doi.org/10.1002/ mnfr.200600173

Guray, E., N. Ocak, A. Altop, S. Cankaya, A. H. Aksoy and E. Ozturk. 2011. Growth performance, meat quality and caecal coliform bacteria count of broiler chicks fed diet with green tea extract. Australas. J. Anim. Sci., 24 (2): 1128-1136. https://doi.org/10.5713/ ajas.2011.10434

Ikeda, I., Y. Imasato and E. Sasaki. 1992. Tea catchins decrease micellar solubility and intestinal absorption of cholesterol in rats. J. Anim. Sci., 35(2): 1127-141. https://doi. org/10.1016/0005-2760(92)90269-2

Jang, S.I., M. J. Hyung, S. L. Hyun, D. A. Rami, K. Keun,K.Suk and M.Wongi.2007.Anticoccidial 
effect of green tea-based diets against Eimeria maxima. J. Poult. Physiol., 14(4): 172-175. https://doi.org/10.1016/j.vetpar.2006.09.005

Kajiya, K., H. Hojo, M. Suzuki, F. Nanjo, S. Kumazawa and T. Nakayama. 2004. Relationship between antibacterial activity of catechin derivatives and their interaction with a model membrane. J. Agric. Food Chem., 52(6): 1514-1519. https://doi.org/10.1021/jf0350111

Kaneko, K., K. Yamasaki, Y. Tagawa, M. Tokunaga, M. Tobisa and M. Furuse. 2001. Effects of dietary japanese green tea powder on growth, meat ingredient and lipid accumulation in broilers. J. Poult. Sci., 38(2): 77-85. https://doi. org/10.2141/jpsa.38.J77

Maron, D.J., G.P. Lu, N.S. Cai, Z.G. Wu, Y.H. Li, H. Chen, J.Q. Zhu, X.J. Jin, B.C. Wouters and J. Zhao. 2003. Cholesterol-lowering effect of a theaflavin-enriched green tea extract: A randomized controlled trial. J. Vet. Med., 16 (3): 1448-1453. https://doi.org/10.1001/ archinte.163.12.1448

Perumalla, A.V.S. and N.S. Hettiarachchy. 2011. Green tea and grape seed extracts potential applications in food safety and quality, review. J. Food Res. Int., 44(4): 827-839. https://doi. org/10.1016/j.foodres.2011.01.022

Shomali, T., M. Najmeh and N. Saeed. 2012. Two weeks of dietary supplementation with green tea powder does not affect performance, $\mathrm{D}$-xylose absorption, and selected serum parameters in broiler chickens. J. Poult. Pathol., 21(5): 1023-
1027. https://doi.org/10.1007/s00580-0111220-9

Sommer, A.P., D. Zhu and T. Scharnweber. 2010. Extraordinary anticancer effect of green tea and red light. J. Anim. Sci., 28(2): 429-430. https:// doi.org/10.1089/pho.2009.2706

Tuzcu,M.,N.Sahin,M.Karatepe,G.Cikim,U.Kilinc and K. Sahin. 2008. Epigallocatechin-3-gallate supplementation can improve antioxidant status in stressed quail. Br. Poult. Sci., 49: 643-648. https://doi.org/10.1080/00071660802298336

Uuganbayar, D., 2004. A study on the utilization of green tea for laying hens and broiler chicks. Dissertation for the degree of Doctor of Philosophy, Sunchon National University, Suncheon, Korea.

Uuganbayar, D., I.H. Bae, K.S. Choi, I.S. Shin, J.D. Firman and C.J. Yang. 2005. Effects of green tea powder on laying performance and egg quality in laying hens. Asian Australas. J. Anim. Sci., 18(2): 1769-1774. https://doi.org/10.5713/ ajas.2005.1769

Yang, C.J., I.Y. Yang, D.H. Oh, I.H. Bae, S.G. Cho, I.G. Kong, D. Uuganbayar, I.S. Nou and K.S. Choi. 2003. Effect of green tea by-product on performance and body composition in broiler chicks. Asian J. Anim. Sci., 16(1): 867-872. https://doi.org/10.5713/ajas.2003.867

Yang, C.S and Z.Y. Wang. 1993. Tea and cancer. J. Natl. Cancer Inst. 85(13): 1038-1049. https:// doi.org/10.1093/jnci/85.13.1038 